\section{PREDICTIVE VALUE OF PRE-TREATMENT HEMATOLOGICAL PARAMETERS TO DEFINITIVE CHEMORADIATION RESPONSE IN LOCALLY ADVANCED VULVAR CARCINOMA}

${ }^{1} \mathrm{~F}$ Abuhijla*, ${ }^{2} \mathrm{R}$ Abuhijilih, ${ }^{2} \mathrm{~S}$ Salah, ${ }^{1} \mathrm{~S}$ Koro, ${ }^{1}$ I Jaradat, ${ }^{3} \mathrm{H}$ Almasri, ${ }^{3}$ I Lataifeh, ${ }^{4} \mathrm{M}$ Shahait, ${ }^{4} \mathrm{M}$ Al-Hussaini, 'I Mohamad. 'King Hussein Cancer Center, Radiation Oncology Department, Jordan; ${ }^{2}$ King Hussein Cancer Center, Medical Oncology Department, Jordan; ${ }^{3}$ King Hussein Cancer Center, Surgical Oncology Department, Jordan; ${ }^{4}$ King Hussein Cancer Center, Pathology Department, Jordan

\subsection{6/ijgc-2021-ESGO.623}

Introduction/Background* To evaluate the predictive value of pre-treatment haematological parameters including haemoglobin level (Hb), neutrophils lymphocyte ratio (NLR) and platelet lymphocyte ratio (PLR) on clinical and radiological response for definitive chemoradiation in locally advanced vulvar cancer.

Methodology Charts of patients who were treated at King Hussein Cancer Centre with definitive chemoradiation for pathologically confirmed locally advanced vulvar carcinoma where reviewed. Response to primary disease was labelled as complete response (CR): if no clinical or radiological residual disease at 12 weeks of completion chemoradiation. Univariate analysis for complete response, progression free survival (PFS) and overall survival (OS) were performed using clinical factors and pre-treatment hematological parameters.

Result(s)* Out of 30 patient who were included in analysis, with mean follow up of 27 months, range (6.7-78); 24 patients achieved CR (80\%) at 12 weeks of treatment completion. On follow up (mean 27 months), 12 patient developed disease progression (40\%) and 9 patients died (30\%). Low pre-treatment NLR $(<3.8)$ was significant prognostic factor for achieving CR $(\mathrm{p}<0.049)$, higher PFS $(\mathrm{p}<0.0067)$ and OS $(\mathrm{p}<0.0001)$. Low pre-treatment PLR showed higher PFS $(\mathrm{p}<0.0276)$, while pretreatment $\mathrm{Hb}$ was not associated with prognosis.

\begin{tabular}{|c|c|c|c|c|c|}
\hline \multirow[t]{2}{*}{ name } & \multirow[t]{2}{*}{ value } & \multirow[t]{2}{*}{ Total } & \multicolumn{2}{|c|}{ Status (response) } & \multirow{2}{*}{$\begin{array}{l}\text { Fisher Exact P- } \\
\text {-value }\end{array}$} \\
\hline & & & CR & DP & \\
\hline \multirow{2}{*}{$\begin{array}{l}\text { HB cutoff } \\
\text { mean }\end{array}$} & $H B<=11.6$ & $15(50.0 \%)$ & $10(41.7 \%)$ & $5(83.3 \%)$ & 0.169 \\
\hline & $H B>11.6$ & $15(50.0 \%)$ & $14(58.3 \%)$ & $1(16.7 \%)$ & \\
\hline \multirow{2}{*}{$\begin{array}{l}\text { NLR cutoff } \\
\text { mean }\end{array}$} & $\mathrm{NLR}<=3.8$ & $21(70.0 \%)$ & $19(79.2 \%)$ & $2(33.3 \%)$ & 0.049 \\
\hline & $N L R>3.8$ & $9(30.0 \%)$ & $5(20.8 \%)$ & $4(66.7 \%)$ & \\
\hline \multirow{2}{*}{$\begin{array}{l}\text { PLR cutoff } \\
\text { mean }\end{array}$} & PLR $<=17.4$ & $19(63.3 \%)$ & $17(70.8 \%)$ & $2(33.3 \%)$ & 0.156 \\
\hline & PLR $>17.4$ & $11(36.7 \%)$ & $7(29.2 \%)$ & $4(66.7 \%)$ & \\
\hline
\end{tabular}

Conclusion* Pre-treatment NLR may be useful as predictive tool to predict clinical and radiological response and oncological outcomes for locally advanced vulvar cancer treated with definitive chemoradiation.

\section{VULVAR CANCER - STILL SILENT KILLER?}

M Szubert*, M Lec, K Molisak, A Rycerz, A Nowak, JR Wilczynski. Medical University of Lodz, Poland, I Department of Gynecology and Obstetrics, Clinic of Surgical and Oncologic Gynecology, Lodz, Poland

\subsection{6/ijgc-2021-ESGO.624}

Introduction/Background* Vulvar cancer is a rare neoplasm of the female genital organs. In 2020, less than $1 \%$ of women in Poland was diagnosed with this disease. Nevertheless, it remains an important clinical problem due to its localization and therapeutic difficulties. The aim of the study was to investigate risk factors, treatment protocols,

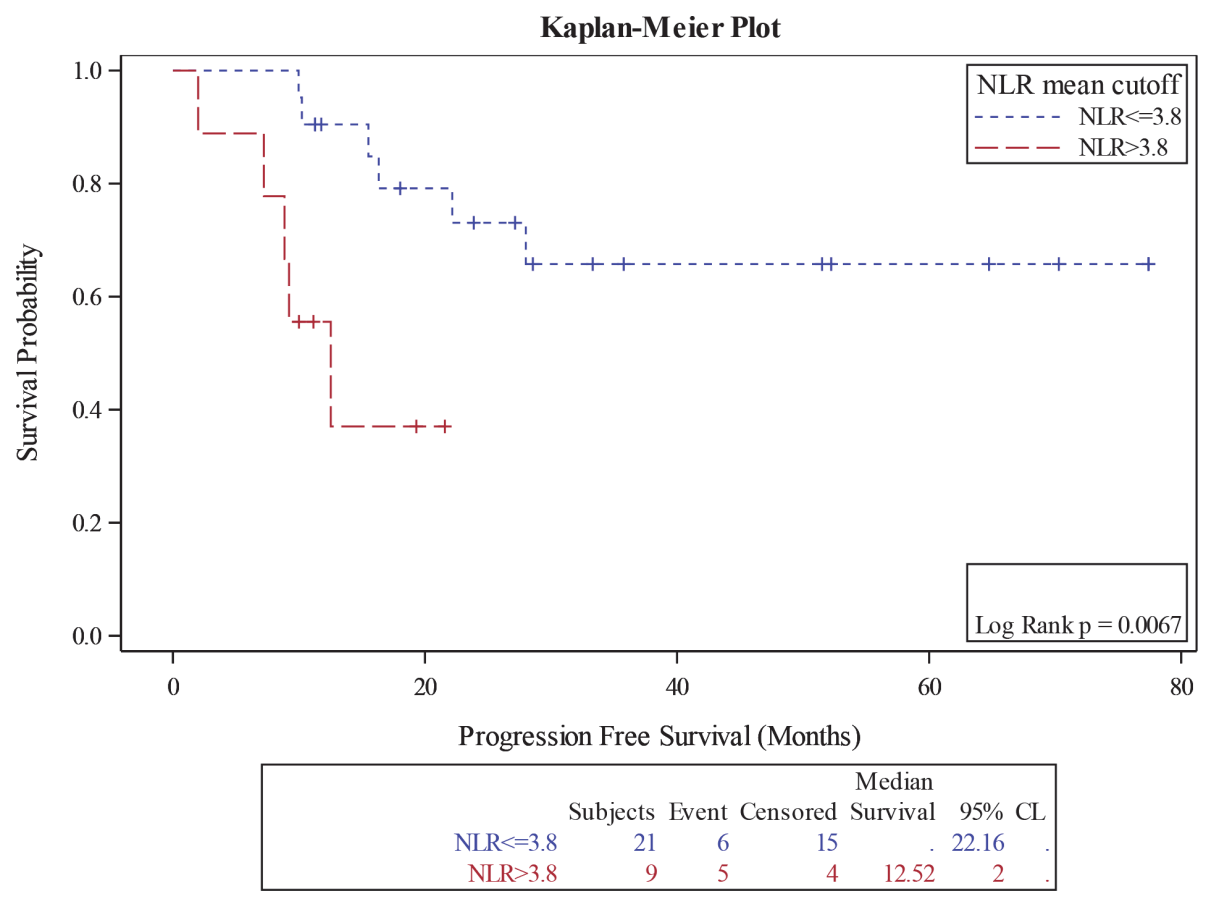

Abstract 490 Figure 1 
treatment outcomes, the prevalence of histopathological types and the quality of life of patients with vulvar lesions.

Methodology The case-control retrospective study involved 138 patients hospitalized in 2010-2020 at the Department of Surgery and Gynecological Oncology, Medical University in Lodz, Poland. The prospective part of the study constituted follow-up that was carried out in the form of a telephone survey. The patients were divided into two groups: with benign lesions (Gr.B) and malignant (Gr.M). The data was statistically processed using the Statistica13.1 program.

Result(s)* Malignant lesions were found in 43 patients (31.16\%). Patients with benign lesions were significantly younger $(57.79 \mathrm{vs} .69 .67 ; \mathrm{p}=0.003)$, had fewer pregnancies (1.76vs.268; $\mathrm{p}=0.0009)$ and gave birth less frequently $(1,35 \mathrm{vs} .2 .35 ; \mathrm{p}=0.0002)$. There was no significant difference between the groups in BMI $(p=0.7141)$, number of miscarriages $(p=0.4469)$, time of menopause $(p=0.1544)$ and smoking $(p=0.5533))$. In group $M 86.05 \%$ of women had squamous cell carcinoma, $4.65 \%$ basal cell carcinoma, $2.33 \%$ vulvar melanoma and $2.33 \%$ extra-mammary Paget's disease. There was a high positive correlation between tumor diameter and length of hospitalization $(\mathrm{R}=0.5523 ; \mathrm{p}=0.0010)$ and $\mathrm{a}$ weak positive correlation between age and length of hospitalization $(\mathrm{R}=0.2835 ; \mathrm{p}=0.0010)$. Five-year survival was found in $77.78 \%$ of women in total. In group $\mathrm{B}$, improvement in the quality of life was noted in $42.86 \%$ of women who started treatment after hospitalization and $36.84 \%$ of women who did not start treatment. The changes in the quality of life between the groups were not statistically significant $(\mathrm{p}=0.9115)$.

Conclusion* The anticipated facts were proven in the studied group: incidence of vulvar cancer was significantly higher in the postmenopausal women, the most common malignant neoplasm was keratinizing squamous cell carcinoma. The time of hospitalization increased with the increase in tumor diameter and the age of the woman. Treatment of women with benign lesions did not significantly improve the quality of life.

\section{LOW-GRADE FIBROMYXOID SARCOMA OF THE VULVA : AN EXCEPTIONAL LOCATION}

K Ben Hamida*, A Jellali, I Zemni, R Chargui, K Rahal, N Boujelbene. Salah Azaiez Institute of Oncology, Department of Surgical Oncology, Tunis, Tunisia

10.1136/ijgc-2021-ESG0.625

Introduction/Background* Low-grade fibromyxoid sarcoma (LGFMS) is a rare and unpredictable soft-tissue fibrous tumor that classically arises in proximal extremities and the trunk.

The occurrence in the female external genitalia is exceptionally described in the literature.

Methodology This report presents two patients with documented LGFMS arising from the vulva who were treated in our institution between 2019 and 2020 .

Result(s)* The patients were aged 22 and 31 years respectively.

Both women presented in another department with painless, slow-growing nodule of the vulva evolving for two years in one case and two months in the other case.

Physical examination found a well-defined subcutaneous mass of the right labia majora of $3 \mathrm{~cm}$ in the first case and
$10 \mathrm{~cm}$ in the second case. The tumors had a smooth surface and hard consistency.

Local excision was performed under local anesthesia.

The histological examination revealed a mesenchymal proliferation of spindle cells occupying the dermis and the hypodermis with positive margins.

Immunochemistry confirmed the diagnosis of LGFMS.

The patients were then referred to our institution.

Pelvic MRI performed in one patient revealed a contrastenhancing epidermal mass of the right posterior part of the vulva measuring $23 \times 13 \mathrm{~mm}$ with no local lymphadenopathy.

CT scan showed no distant metastasis in both patients.

After a multidisciplinary consultation meeting, we decided to perform a tumor bed resection.

The final pathologic testing revealed no residual tumor with negative final margins.

No adjuvant treatment was considered necessary to complete the treatment.

The current follow-up of the two patients is free of recurrence.

Conclusion* LGFMS are among the least common histologic subtypes of sarcoma arising in the lower genital tract, and its benign appearance can be misdiagnosing.

Surgery with immunohistological examination remain the only way to establish the diagnosis and guide the treatment.

\section{TERMS AND DEFINITIONS TO DESCRIBE SONOGRAPHIC FEATURES OF LYMPH NODES: CONSENSUS OPINION FROM THE VULVAR INTERNATIONAL TUMOR ANALYSIS (VITA) GROUP}

${ }^{1} \mathrm{D}$ Fischerova*, ${ }^{2,3} \mathrm{G}$ Garganese, ${ }^{4} \mathrm{H}$ Reina, ${ }^{5} \mathrm{SM}$ Fragomeni, ${ }^{1} \mathrm{D}$ Cibula, ${ }^{6} \mathrm{O}$ Nanka, ${ }^{7} \mathrm{~T}$ Rettenbacher, ${ }^{3,5} \mathrm{AC}$ Testa, ${ }^{8,9} \mathrm{E}$ Epstein, ${ }^{10}$ I Guiggi, ${ }^{1} \mathrm{~F}$ Frühauf, ${ }^{4} \mathrm{G}$ Manegold, ${ }^{3,5} \mathrm{G}$ Scambia, ${ }^{11,12} \mathrm{~L}$ Valentin. ${ }^{1}$ First Faculty of Medicine, Charles University and General University Hospital in Prague, Department of Obstetrics and Gynecology, Praha 2, Czech Republic; ${ }^{2}$ Mater Olbia Hospital, Gynecology and Breast Care Center, Olbia, Italy; ${ }^{3}$ Università Cattolica del Sacro Cuore, Dipartimento Scienze della Vita e Sanità Pubblica, Rome, Italy; ${ }^{4}$ Women's Hospital, University Hospital of Basel, Department of Gynecological Ultrasound and Prenatal Diagnostics, Basel, Switzerland; ${ }^{5}$ Fondazione Policlinico Universitario Agostino Gemelli, IRCCS, Dipartimento Scienze della Salute della Donna, del Bambino e di Sanità Pubblica, Rome, Italy; ${ }^{6}$ Institute of Anatomy, First Faculty of Medicine, Charles University, Prague, Czech Republic; 'Universitäts Klinik für Radiologie II, Department Radiologie , Innsbruck, Austria; ${ }^{8}$ Karolinska Institute, Sodersjukhuset, Department of Clinical Science and Education, Stockholm, Sweden; ${ }^{9}$ Sodersjukhuset, Department of Obstetrics and Gynecology, Stockholm, Sweden; ${ }^{10}$ North West Tuscany Hospital, Department of Obstetrics and Gynecology, Livorno, Italy; ${ }^{11}$ Skåne University Hospital, Department of Obstetrics and Gynecology, Malmö, Sweden; ${ }^{12}$ Lund University, Department of Clinical Sciences Malmö, Lund, Sweden

\subsection{6/ijgc-2021-ESGO.626}

Introduction/Background* There is, as yet, no international consensus on ultrasound assessment of lymph nodes in any disease or medical condition. The lack of standardized ultrasound nomenclature to describe lymph nodes makes it difficult to compare results from different ultrasound studies and to find reliable ultrasound features for distinguishing non-infiltrated lymph nodes from those infiltrated by cancer or lymphoma.

Methodology The Vulvar International Tumor Analysis (VITA) collaborative group was established involving gynecologists, gynecologic oncologists and radiologists with expertise in gynecologic cancer, particularly in the ultrasound staging and treatment of vulvar cancer. The steering committee for the study held special meeting to discuss the 